Available online on 15.10 .2018 at http://jddtonline.info

Journal of Drug Delivery and Therapeutics

Open Access to Pharmaceutical and Medical Research

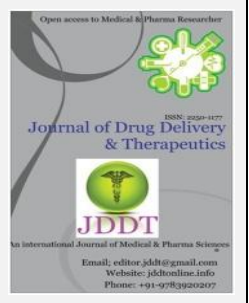

Open $\odot$ Access

Review Article

\title{
RECENT PROMISING ADVANCES IN DEVELOPMENT OF ANTIMICROBIAL AGENTS: A REVIEW
}

\author{
Mudasir Maqbool ${ }^{1,}$ Geer Mohamed Ishaq ${ }^{1 *}$ \\ ${ }^{1}$ Department of Pharmaceutical Sciences, University of Kashmir, Hazratbal Srinagar-190006, Jammu and Kashmir, India
}

\begin{abstract}
Antimicrobial resistance is a serious global threat. There is a global menace of antibiotic resistant "super bug", though the extent and the severity of the problem varies. Resistance hampers therapeutic options and drives clinicians to use newer and more expensive drugs. In serious cases, multi-resistance provides no treatment options. To overcome resistance, a continuous supply of new antibiotics offers an obvious way; but the pipeline of agents in development by the Pharmaceutical industry is very limited. There is an ever-evolving need to develop and evaluate newer alternative strategies for countering a worsening clinical situation to overcome resistance and reduce the morbidity and mortality associated with infections caused by antibiotic-resistant bacteria. The widespread distribution of Antimicrobial resistance has not been paralleled by the development of newer antimicrobials. This happens due to the process of drug discovery and clinical trials of new antimicrobials taking longer time and only a fewer new agents been approved for use. In modern era, where obstacles like chemo-resistance and mutations torment medicine, scientists across the world are looking to adapt lateral approaches in encountering diseases.
\end{abstract}

Keywords: antimicrobial resistance, super bug, antibiotics

Article Info: Received 04 Sep, 2018; Review Completed 01 Oct 2018; Accepted 03 Oct 2018; Available online 15 Oct 2018

$\square=0$ Cite this article as:

Maqbool M, Ishaq GM, Recent promising advances in development of antimicrobial agents: a review, Journal of Drug Delivery and Therapeutics. 2018; 8(5-s):82-86 DOI: http://dx.doi.org/10.22270/jddt.v8i5-s.1959

*Address for Correspondence:

Geer Mohamed Ishaq, Department of Pharmaceutical Sciences, University of Kashmir, Hazratbal Srinagar-190006, Jammu and Kashmir, India

\section{INTRODUCTION}

Antimicrobial resistance is a serious global threat. There is a global menace of antibiotic resistant "super bug", though the extent and the severity of the problem varies ${ }^{1,}$

2 . Resistance hampers therapeutic options and drives clinicians to use newer and more expensive drugs. In serious cases, multi-resistance provides no treatment options. To overcome resistance, a continuous supply of new antibiotics offers an obvious way; but the pipeline of agents in development by the Pharmaceutical industry is very limited. There is an ever-evolving need to develop and evaluate newer alternative strategies for countering a worsening clinical situation to overcome resistance and reduce the morbidity and mortality associated with infections caused by antibiotic-resistant bacteria $^{3,4}$. The widespread distribution of Antimicrobial resistance has not been matched up to by the development of newer antimicrobials. This occurs because the process of drug discovery and clinical trials of newer antimicrobials taking longer time and only a fewer new agents been approved for use ${ }^{5}$.

In this review paper, we will briefly focus on novel antimicrobial strategies tackling antimicrobial resistance.

\section{DEVELOPMENT OF NEW ANTIMICROBIALS}

Majority of antimicrobial obtained from different natural sources tend to cause inhibition of various cellular processes viz. DNA replication, cell wall biosynthesis, and protein synthesis. However with the increase of AMR, the investigation of alternative essential cellular processes has been screened, as the drug targets for the next progeny of antimicrobials ${ }^{6}$. For instance, bedaquiline is a drug targeting the F0F1 ATP synthase ${ }^{7}$. 
Irrespective of architectural conservation of the bc1 complex in many species, Q203- an optimized imidazopyridine amide selectively inhibits the respiratory cytochrome bc1 complex in mycobacteria similar to bedaquiline ${ }^{8}$. Another promising strategy for antimicrobial activity can be caused by attacking the central cell wall division mediator FtsZ, which leads to the inhibition of Bacterial cell division. This antimicrobial attack can occur either by interfering with the normal dynamics and activity of FtsZ during the cell cycle. It can also lead to the activation of a protease bacterial enzyme to cause destruction of FtsZ, therefore inflicting microbe death during destructive manner ${ }^{9}$.

a self-

Another attractive newer site of drug action- an asymmetric outer cell membrane in Gram-negative bacteria has been observed. This outer membrane is a permeability barrier and tends to save the cell from the various external stresses and forces like the presence of antimicrobials. By interacting with the selected $\beta$-barrel outer membrane proteins including BamA and $\mathrm{LptD}$, a novel macrocyclic peptide, JB-95, shows selective disruption of the outer cell membrane of the Gram negative bacteria ${ }^{10,11,12}$. Likewise, a target for removal of Pathogens is by targeting the bacterial protein secretion pathway. Employing the Sec-pathway for antimicrobial activity is based on two principles; SecA, the energy driven motor protein causing the movement of pre-proteins across the membrane and Type I signal peptidase enzyme, that leads to removal of signal peptide to cause release of mature proteins from the cytoplasmic membrane $^{13}$. Another strategy to overcome resistance is by employing them in combination with the standard antimicrobial drugs. AMR occurs by: inactivation of drug, reduced permeability of the drug, change in drug target and increase in the efflux of the drug. In response to physiological signals, efflux pumps serve important physiological functions ${ }^{14-17}$. Many recent researches have tried to revert the resistance phenotype of efflux pump activation ${ }^{18}$. Adding efflux pump inhibitors partially improved the potency and efficacy of the drug in anti-Mycobacterium drug therapy ${ }^{19}$. Designing and structuring of compounds with $\beta$-lactam is a promising approach to the development of of metallo- $\beta$-lactamase inhibitors such as penicillin derivatives, carbapenem derivatives, cephalosporin derivatives, etc ${ }^{20}$.

\section{DEVELOPMENT OF ICHIP DEVICE}

Procedure to cultivate microorganisms under lab conditions remained the same for so many years and a large population of these microorganisms failed to grow. This is called the Great plate Anomaly which is the observation that most of the microbes seen in the microscope cannot currently be grown under laboratory conditions, some may actually be nonviable, and others are viable but non culturable ${ }^{21}$. The researchers couldn't study the chemicals that were released by these microbes which showed antimicrobial activity and which could serve as a potential for the synthesis of antibiotics. However, many years later, a device was made which could grow many samples together. This new device was known as iChip. Researchers had to dip this chip in the bacterial stock, added with agar, which locked the sample inside the secure diffusion membrane, placed in a large stock sample from the original environment. Every cell then acts as a small diffusion chamber. Thousands of new bacteria have now been cultured by iChip and development of newer antibiotics for e.g. Teixobacctin ${ }^{22-26}$.

\section{PEPTIDOMIMETIC ANTIMICROBIALS}

Antimicrobials that occur naturally or can be synthesized as antimicrobial peptides (AMPs) could form a basis for the development of newer functional classes of antimicrobials 27, 28. Antimicrobial peptides, being selective agents, show their activity on the prokaryotic membrane. These cause membrane modifications which leads to total membrane disintegration ${ }^{29,30,31}$. However, the clinical utilization of AMPs has been limited. The AMPs show high susceptibility to proteolytic enzymes, may cause toxicity due to larger quantities of drug needed for therapy and above all cost manufacturing ${ }^{32}$. Also other characteristics that may restrict use of AMPs include higher protein binding and high clearance causing a decreased half life. To overcome these limitations, generation of proteolytically resistant moieties of natural peptides by complete or partial substitution of L-moieties with synthetic or non natural D- or B- moieties is been studied. McGrath et al. synthesized a newer peptide called as (KLAKLAK)2 which showed decreased toxicity to the mammalian cells $^{33,34}$.

\section{FimH-INHIBITORS}

Uropathogenic E. coli (UPEC), the organism responsible for causing more than $85 \%$ of all Urinary tract infections have progressively become more resistant to antibiotics. AMR is not just restricted to community agents but broad spectrum antimicrobials like Beta-lactams and fluoroquinolones, thereby causing a therapeutic problem $^{35,36}$. UPEC invades the urinary tract by using type 1 pili tipped with the FimH adhesin to attach to mannosylated receptors present on the luminal surface of the human bladder epithelial cells. Thereby causing the process of colonization and invasion of bacteria in the bladder. As a part of innate defense mechanism, bladder cells can expel UPEC from the epithelial cells, but a single bacterial cell can replicate to 104-105 which can then combine in a type 1 pilus-dependent manner to form an intracellular bacterial community (IBC) within the epithelial cell. After IBC mature, bacteria detach from the IBC and spread to other neighbouring cells to form several further IBCs. FimH is necessary for invasion, IBC formation and the capability of bacteria to invade and colonise the bladder. Therefore, agents that target the FimH are been developed. In every strain of E.Coli, the mannose-binding pocket of FimH is composed of amino acid residues. Changes in these residues which are same in all strains disrupt mannose binding and attenuate virulence ${ }^{37}$. Basically FimH inhibitors were derived from mannosides that consist of D-mannose units. FimH inhibitors show excellent cellular potency and low molecular weight. Cusumano et al. ${ }^{38}$ generated a series of 6 candidates with an aim to 
generate orally available agents which can be a therapeutic option to treat and prevent chronic UTI ${ }^{39,40}$.

\section{QUORUM SENSING APPROACHES}

Management of P. aeruginosa infections involves complex fluid and ventilator management, definitive surgical debridement and advanced technologies. In addition, various antimicrobial agents are also employed against antibiotic resistant strains of $\mathrm{P}$. aeruginosa such as colisitin. Studies in P. aeruginosa pathogenesis has revealed a complex regulatory communication system, called as quorum sensing (QS), which is responsible for controlling about $10 \%$ of $\mathrm{P}$. aeruginosa genes ${ }^{41}$. Quorum sensing (QS), is a cell-density-dependent process, which is based on the release of low-molecular weight moieties that co-ordinate gene expression in a given cell population ${ }^{42}$. P. aeruginosa releases moieties, in response to high population density, which act as specific chemical signals. These chemical signals control the synthesis of virulence factors that manifest acute infection. The QS regulator termed as multiple virulence factor regulator (MvfR) helps in controlling the expression of majority acute virulence of $\mathrm{P}$. aeruginosa's factors that manifest acute infection in addition to several various excreted anthranilic acid derivatives, majority of which constitute the 4-hydroxy-2akylquinolines (HAQs) family. These HAQs, in combination with MvfR, serve in the positive regulation of the transcription of two operons which encode biosynthesis of the virulence molecules. Que et al. ${ }^{43}$ showed the presence of HAQs in necrotic burn tissue, fat, pus and liquefied fat and drainage liquid. They proposed that by targeting QS using anti-QS inhibitors may reduce infections caused by MDR bacteria. Hence QS could be a promising drug target for new antimicrobials because it controls pathogenesis of disease and is evolutionarily conserved among pathogenic bacteria ${ }^{44}$.

\section{NEWER TARGETS FOR THE NEXT GENERATION ANTIMICROBIALS FOR COMBATING DRUG RESISTANCE}

In today's world various good potent antimicrobials are used. However with the development of antimicrobial resistance, these have been rendered almost less effective. Mostly they act as bacteriostatic and work either by inhibition of protein or cell-wall synthesis. This situation stresses on the need for creation and designing of newer antimicrobial agents with exploring newer targets.

\section{Targeting bacterial proteins}

Antimicrobials can act on newer bacterial proteins for e.g. by inhibiting the enzyme $\beta$-ketoacyl-acyl-carrierprotein synthase I/II which is required for fatty-acid biosynthesis in bacteria. One such agent, Platensimycin is in pre-clinical trials which targets enzymes involved in the fatty acid biosynthesis ${ }^{45}$.

\section{Targeting the virulence factors}

Toxin function could be a potential target for virulence inhibitors. For instance catalytic activity of $B$. anthracis lethal factor; toxin delivery by blocking various bacterial systems such as type II or type III secretion; virulence gene expression regulated by virulence gene and bacterial attachment to host cells ${ }^{46}$.

\section{Modulating the host response pathways}

Antimicrobial peptides that activate the adaptive immune response to combat infections are produced by toll-like receptor activators and modulators. These may potentially have an antimicrobial role ${ }^{47}$.

\section{Therapeutic use of bacteriophages}

Genes can be delivered via delivery bacteriophage that can bind and inactivate bacterial DNA for e.g. small, acid-soluble protein (SASPs) genes could be delivered to $S$. aureus by a $S$. aureus-specific delivery bacteriophage; this results in the release of SASPs which then bind to and cause inactivation of bacterial DNA ${ }^{48}$.

\section{Antibiotics with bioenhancers}

Bioenhancer tend to increase the systemic availability and potency of a drug with which it is administered with. The bioenhancer doesn't possess any pharmacological activity of its own at the therapeutic dose used ${ }^{49}$. It is employed to increase the potency and efficacy of the commonly used antibiotics. For e.g. Tetracycline with non-antibiotic Loperamide, increases the activity of tetracycline by enhancing its permeability ${ }^{50}$.

\section{Novel strategies for antibacterial drug discovery}

Majority of the current traditional approaches for antibacterial drug discovery have become saturated. This has paved way for the development and exploration of newer strategies in antibacterial drug discovery.

\section{Antimicrobial peptides}

AMPs work by interfering with metabolism, acting on cytoplasmic components and causing disruption of cell membranes. These work as immunomodulators, increase the immunity and therefore serve as newer potential therapeutic target. Examples are dermaseptin (from frog skin), defensin and crustin (from crustacean family) etc. omiganan and pexiganan are the drugs under clinical trials in this class ${ }^{51}$.

\section{Engineering a prodrug}

Employing a prodrug form of a drug, which gets transformed into a highly potent drug within the microorganism, is another strategy. This can help to bypass the common resistance mechanisms and thereby serves as a promising avenue for new drug development.

\section{Engineering hybrid antibacterial drugs}

Combination of two drugs can serve as potential to overcome antibiotic resistance. For e.g. Mutilinquinolone hybrid AM-3005 (Type II topoisomerase inhibitor + a protein synthesis inhibitor) can cover two targets simultaneously ${ }^{52}$.

\section{Alternative form of drug delivery methods}

Unorthodox forms of drug delivery methods can be employed such as treatment of chronic $P$. aeruginosa lung infections in cystic fibrosis patients by using inhaled amikacin available as nanoscale liposomal 
formulation. Advantages of this are biofilm penetration and sustained release from liposomes and hence serve as alternative form of drug delivery method ${ }^{53}$.

\section{Herbal derivatives as lead molecules}

Plant drugs and their derivatives can work as lead molecules and play a vital role in new drug discovery and development. A recent study of Nautiyala et al.

\section{REFERENCES}

1. Dr. Margaret Chan, Director General-World Health Organization. Available from htpp://www.who.int/world-healthday/2011

2. Appelbaum PC. 2012 and beyond: Potential for the start of a second pre-antibiotic era? J Antimicrob Chemother. 2012; 67(9):2062-8. doi: 10.1093/jac/dks213.

3. Fox JL. The business of developing antibacterials. Nat Biotechnol 2006; 24:1521-8.

4. Projan SJ, Shales DM. Antibacterial drug discovery: is it all downhill from here? Clin Microbial Infect, 2004; 10 (Suppl 4):18 22.

5. Chang Q., Wang W., Regev-Yochay G., Lipsitch M., and Hanage W.P. Antibiotics in agriculture and risk to human health: how worried should we be ? Evol Appl. 2015 Mar; 8(3): 240247. doi: $10.1111 /$ eva. 12185

6. Murima P, McKinney JD, Pethe K. Targeting bacterial central metabolism for drug development. Chem Biol. 2014; 21(11):142332. doi: 10.1016/j.chembiol.2014.08.020.

7. Andries K, Verhasselt P, Guillemont J, Göhlmann HW, Neefs JM, Winkler H, Van Gestel J, Timmerman P, Zhu M, Lee E, Williams P, de Chaffoy D, Huitric E, Hoffner S, Cambau E, Truffot-Pernot C, Lounis N, Jarlier V. A diarylquinoline drug active on the ATP synthase of Mycobacterium tuberculosis. Science. 2005 Jan 14; 307(5707):223-7.

8. K Pethe, P Bifani, J Jang, S Kang, S Park, S Ahn S., et al.

Discovery of Q203, a potent clinical candidate for the treatment of tuberculosis .Nat Med. 2013; 19(9):1157-60. doi:

10.1038/nm.3262.

9. Sass P., and Brötz-Oesterhelt H. Bacterial cell division as a target for new antibiotics. Curr Opin Microbiol. 2013; 16(5):52230. doi: 10.1016/j.mib.2013.07.006.

10. Krol,E., de Sousa Borges, A., da Silva, I., Polaquini, C. R., Regasini, L. O., Ferreira, H., et al. (2015). Antibacterial activity of alkyl gallates is a combination of direct targeting of FtsZ and permeabilization of bacterial membranes. Front Microbiol. 2015; 29(6):390. doi: 10.3389/fmicb.2015.00390.

11. Foley T. L., and Simeonov, A. Targeting iron assimilation to develop new antibacterials. Expert Opin Drug Discov. 2012; 7(9):831-47. doi: 10.1517/17460441.2012.708335.

12. Urfer M., Bogdanovic J., Lo Monte F., Moehle K., Zerbe K., Omasits U., et al. A peptidomimetic antibiotic targets outer membrane proteins and disrupts selectively the outer membrane in Escherichia coli. J Biol Chem. 2016; 291(4):1921-32. doi: 10.1074/jbc.M115.691725.

13. Rao C. V. S., De Waelheyns E., Economou A., and Anné J. Antibiotic targeting of the bacterial secretory pathway. Biochim Biophys Acta. 204; 1843(8):1762-83. doi:

10.1016/j.bbamcr.2014.02.004.

14. Hooper D. C., and Jacoby G. A. Mechanisms of drug resistance: quinolone resistance. Ann N Y Acad Sci. 2015; 1354:12-31. doi: 10.1111/nyas.12830.

15. Shaw K. J., Rather P. N., Hare R. S., and Miller, G. H. Molecular genetics of aminoglycoside resistance genes and familial relationships of the aminoglycoside-modifying enzymes. Microbiol Rev. 1993; 57(1):138-63.

16. Nikaido, H. Molecular basis of bacterial outer membrane permeability revisited. Microbiol. Microbiol Mol Biol Rev. 2003; 67(4):593-656.

17. Sun J., Deng Z., and Yan A. Bacterial multidrug efflux pumps: mechanisms, physiology and pharmacological

exploitations. Biochem Biophys Res Commun. 2014: 453(2):25467. doi: 10.1016/j.bbrc.2014.05.090. observed that $1 \mathrm{hr}$ treatment with medicinal smoke, lead to $94 \%$ reduction of bacterial counts ${ }^{54}$.

\section{ACKNOWLEDGEMENT}

We would like to thank Department of Pharmaceutical Sciences, University of Kashmir, Hazratbal Srinagar190006 for their support and valuable suggestions.

18. Opperman, T. J., and Nguyen, S. T. Recent advances toward a molecular mechanism of efflux pump inhibition. Front Microbiol 2015; 6:421. doi: 10.3389/fmicb.2015.00421.

19. Pule C. M., Sampson S. L., Warren R. M., Black P. A., van Helden P. D., Victor T. C., et al. Efflux pump inhibitors: targeting mycobacterial efflux systems to enhance TB therapy. J Antimicrob Chemother. 2016; 71(1):17-26. doi: 10.1093/jac/dkv316.

20. King D.T., and Strynadka N. C. (2013). Targeting metallobeta-lactamase enzymes in antibiotic resistance. Future Med Chem. 2013; 5(11):1243-63. doi: 10.4155/fmc.13.55.

21. Dharmesh Harwani The Great Plate Count Anomaly and the Unculturable Bacteria International Journal of Scientific Research, 2013; 2(9).

22. Cesar A. Arias, M.D., Ph.D., and Barbara E. Murray, M.D. A New Antibiotic and the Evolution of Resistance., N Engl J Med. $2015 ; 3$ 72(12):1168-1170.

23. Ling LL, Schneider T, Peoples AJ et al. A new antibiotic kills pathogens without detectable resistance. Nature. 2015;

517(7535):455-9. doi: 10.1038/nature14098.

24. Kaeberlain et al, "Isolating 'uncultivable' Microorganisms in Pure Culture in Simulated Natural Environment,'Science 2002; 296(5570):1127-1129.

25. Nichols et al. Use of ichip for high-throughput in situ cultivation of "uncultivable" microbial species. Appl. Environ. Microbiol. 2010; 76(8):2445-2450

26. Fleming, A. On the antibacterial action of cultures of a penicillium, with special reference to their use in the isolation of B. influenzae. Br J Exp Pathol. 1929; 10(3):226-236.

27. Marr AK, Gooderham WJ, Hancock RE. Antibacterial peptides for therapeutic use: obstacles and realistic outlook. Curr Opin Pharmacol. 2006; 6(5):468-72.

28. Hancock RE, Lehrer R. Cationic peptides: a new source of antibiotics. Trends Biotechnol. 1998; 16(2):82-8.

29. Brogden KA. Antimicrobial peptides: pore formers or metabolic inhibitors in bacteria? Nat Rev Microbiol. 2005; 3(3):238-50.

30. Shai Y. Mechanism of the binding, insertion and destabilization of phospholipid bilayer membranes by alphahelical antimicrobial and cell non-selective membrane-lytic peptides. Biochim Biophys Acta. 1999; 1462(1-2):55-70. 31. Huang Y, Huang J, Chen Y. Alpha-helical cationic antimicrobial peptides: relationships of structure and function. Protein Cell. 2010; 1(2):143-52. doi: 10.1007/s13238-010-0004-3. 32. Peters BM, Shirtliff ME, Jabra-Rizk MA. Antimicrobial peptides: primeval molecules or future drugs? PLoS Pathog. 2010; 6(10):e1001067. doi: 10.1371/journal.ppat.1001067.

33. McGrath DM, Barbu EM, Driessen WHP, Lasco TM, Tarrand JJ, Okhuysen PC, Kontoyiannis DP, Sidman RL, Pasqualini R, Arap W. Mechanism of action and initial evaluation of a membrane active all-D-enantiomer antimicrobial peptidomimetic. Proc Natl Acad Sci USA. 2013; 110:3477-82.

http://dx.doi.org/10.1073/pnas.1221924110.

34. Barbu EM, Shirazi F, McGrath DM, Albert N, Sidman RL, Pasqualini R, Arap W, Kontoyiannis DP. An antimicrobial peptidomimetic induces mucorales cell death through mitochondria-mediated apoptosis. PLoS One. 2013; 8(10):e76981. doi: 10.1371/journal.pone.

35. Griebling TL. Urologic diseases in America project: trends in resource use for urinary tract infections in women. J Urol. 2005; 173(4):1281-7. 
36. Gupta K, Hooton TM, Stamm WE. Increasing antimicrobial resistance and the management of uncomplicated communityacquired urinary tract infections. Ann Intern Med. 2001; 135(1):41-50.

37. Chen SL, Hung CS, Pinkner JS, Walker JN, Cusumano CK, Li Z, Bouckaert J, Gordon JI, Hultgren SJ. Positive selection identifies an in vivo role for FimH during urinary tract infection in addition to mannose binding. Proc Natl Acad Sci USA. 2009; 106(52):22439-44. doi: 10.1073/pnas.0902179106.

38. Cusumano CK, Pinkner JS, Han Z, Greene SE, Ford BA, Crowley JR, Henderson JP, Janetka JW, Hultgren SJ. Treatment and prevention of urinary tract infection with orally active FimH inhibitors. Sci Transl Med. 2011; 3(109):109ra115. doi: 10.1126/scitranslmed.3003021.

39. Han Z, Pinkner JS, Ford B, Chorell E, Crowley JM, Cusumano CK, Campbell S, Henderson JP, Hultgren SJ, Janetka JW. Lead optimization studies on FimH antagonists: discovery of potent and orally bioavailable ortho-substituted biphenyl mannosides. J Med Chem. 2012; 55(8):3945-59. doi: 10.1021/jm300165m. 40. Tran N, Mir A, Mallik D, Sinha A, Nayar S, Webster TJ. Bactericidal effect of iron oxide nanoparticles on Staphylococcus aureus. Int J Nanomedicine. 2010; 5:277-283.

41. Hazan R, He J, Xiao G, Dekimpe V, Apidianakis Y, Lesic B, Astrakas C, Déziel E, Lépine F, Rahme LG. Homeostatic interplay between bacterial cell-cell signaling and iron in virulence. PLoS Pathog. 2010 Mar 12;6(3):e1000810. doi:

10.1371/journal.ppat.1000810.

42. Ng W, Bassler BL. Bacterial quorum-sensing network architectures. Annu Rev Genet.2009; 43:197-222. doi:

10.1146/annurev-genet-102108-134304.

43. Que Y, Hazan R, Ryan CM, Milot S, Lépine F, Lydon M, Rahme LG. Production of Pseudomonas aeruginosa Intercellular Small Signaling Molecules in Human Burn Wounds. J Pathog.2011; 2011:549302. doi: 10.4061/2011/549302. 44. Lesic B, Lépine F, Déziel E, Zhang J, Zhang Q, Padfield K, Castonguay M, Milot S, Stachel S, Tzika AA, Tompkins RG, Rahme LG. Inhibitors of pathogen intercellular signals as selective anti- infective compounds. PLoS Pathog. 2007; 3(9):1229-39.
45. Habich D, Von Nussbaum F. Platensimycin, a new antibiotic and "superbug challenger" from nature. ChemMedChem. 2006; 1(9):951-4.

46. Clatworthy AE, Pierson E, Hung DT. Targeting virulence: A new paradigm for antimicrobial therapy. Nat Chem Biol. 2007; 3(9):541-8.

47. Liu PT, Stenger S, Li H, Wenzel L, Tan BH, Krutzik SR, et al. Toll-like receptor triggering of a vitamin D-mediated human antimicrobial response. Science. 2006; 311(5768):1770-3. 48. Wilkinson A, Holmes S, Pitts K. Proceedings of the 47th Interscience Conference on Antimicrobial Agents and Chemotherapy. Chicago, USA: 2007. Sep 17-20, SASP: A novel antibacterial DNA binding protein and its targeted delivery to Staphylococcus aureus. Abstract F1-2132.

49. Randhawa GK, Kullar JS, Rajkumar. Bioenhancers from mother nature and their applicability in modern medicine. Int $\mathrm{J}$ Appl Basic Med Res. 2011; 1(1):5-10. doi: 10.4103/2229516X.81972.

50. Ejim L, Farha MA, Falconer SB, Wildenhain J, Coombes BK, Tyers M, et al. Combinations of antibiotics and nonantibiotic drugs enhance antimicrobial efficacy. Nat Chem Biol. 2011; 7(6):348-50. doi: 10.1038/nchembio.559.

51. Coutinho HD, Lobo KM, Bezerra DA, Lobo I. Peptides and proteins with antimicrobial activity. Indian J Pharmacol. 2008; 40:3-9.

52. Asahina Y, Nagae O, Sato T, Takadoi M, Ohata K, Shibue T, et al. Proceedings of the 48th Annual Interscience Conference on Antimicrobial Agents and Chemotherapy (ICAAC) and the Infectious Disease Society of America (IDSA) 46th Annual Meeting. Washington DC: 2008. Oct 25-28, AM-3005: Synthesis and in vitro antibacterial activity of novel mutilin-quinolone hybrid antibacterial agent (F1-2030).

53.Meers P, Neville M, Malinin V, Scotto AW, Sardaryan G, Kurumunda R, et al. Biofilm penetration, triggered release and in vivo activity of inhaled liposomal amikacin in chronic Pseudomonas aeruginosa lung infections. J Antimicrob Chemother. 2008; 61(4):859-68. doi: 10.1093/jac/dkn059.

54. Nautiyal CS, Chauhan PS, Nene YL. Medicinal smoke reduces airborne bacteria. J Ethnopharmacol. 2007; 114(3):446-51. 